\title{
Sanayi Devrimi Sonrası Avrupa ve Amerika'da Ticaret Eğitimi
}

\section{Business Education in Europe and in the United States after the Industrial Revolution}

\author{
Sabri Burak Arzova ${ }^{1} \odot$ \\ 'Prof. Dr., Marmara Üniversitesi, İşletme Fakültesi, İstanbul, Türkiye \\ ORCID: S.B.A. 0000-0001-9616-4197
}

\section{öz}

Yeni buluşların hız kazanması ve buhar gücünün keşfedilip, buhar gücü ile çalışan makinelerin üretimde kullanılmaya başlanması ile birlikte bu yeni dönem Sanayi Devrimi olarak adlandırılmıştır. İlk olarak Avrupa'da Birleşik Krallıkta 18. Yüzyılda başlayan Sanayi Devrimi ile birlikte sermaye birikimi de artmaya başlamıştır.

Zamanla tüm dünyaya yayılan yeni dönem ülke nüfuslarında arışa, tarımın yavaş yavaş terk edilerek sanayiye yönelmeye, köyden kente göçe sebebiyet vermiştir. Bireylerin satın alma güçlerinin artmaya başlaması, ülkelerin de karşılıklı olarak ticaretlerinin artmasına neden olmuştur. Sanayi devriminin etkisiyle artan ticaret beraberinde nitelikli işgücüne duyulan ihtiyacı, bu ihtiyaç yetişmiş tüccarlara duyulan ihtiyacı tetikledi. Sanayi devrimi ile birlikte ticaret eğitimine duyulan ihtiyaç da aynı oranda artış gösterdi.

Gerek Avrupa'da gerekse de Amerika'da Sanayi Devrimi ile başlayan ticaret eğitimi, bugünün büyük Ticaret Okullarının köklerini oluşturmakta. Bu çalışmada Avrupa ve Amerika'da ticaret eğitiminin nasıl başladığı, hangi aşamaları kaydettiği ve eğitimlerin nasıl verildiği incelenmiştir.

Anahtar kelimeler: Sanayi Devrimi, Büyüme, Kalkınma, Ticaret Eğitimi, Avrupa'da Ticaret Eğitimi, Amerika'da Ticaret Eğitimi

\section{ABSTRACT}

The period that started with the acceleration of new inventions and the discovery and usage of steam powered machines in production was called Industrial Revolution. Firstly, in Europe, and particularly in the UK, capital accumulation started to increase with the Industrial Revolution which started in the $18^{\text {th }}$ century.

In time, the new era spreading all over the world created population growth, and gradually transformed societies from agriculture to industry, and triggered migration from village to city. As the purchasing power of individuals started to increase, the mutual trade volume of the countries also increased. The increasing trade due to the effect of the industrial revolution triggered the need for qualified labor, and this triggered the need for qualified merchants. With the industrial revolution, the need for business education has increased at the same rate.

Business education, which began with the Industrial Revolution in both Europe and America, forms the roots of today's major Business Schools. This study examines how business education started in Europe and America, which stages it recorded and how this education was given.

Keywords: Industrial Revoltion, Economic Growth, Development, Business Education, Business Education in Europe, Business Education in the U.S.

Başvuru/Submitted: 14.07.2019 Kabul/Accepted: 26.07.2019

Sorumlu yazar/Corresponding author: Sabri Burak Arzova / burakarzova@marmara.edu.tr

Atıf/Citation: Arzova, S. B. (2019). Sanayi devrimi sonrası Avrupa ve Amerika'da ticaret eğitimi. Muhasebe Enstitüsü Dergisi - Journal of Accounting Institute, 61, 9-24. https://doi.org/10.26650/MED.2019591776 


\section{EXTENDED ABSTRACT}

The road to prosperity with the Industrial Revolution was now through production and sale to the world through free trade policies and instruments. Until then, the exploitation of precious metals and the accumulation of commercial capital in the world through international trade had continued to increase since the second half of the century. In fact, the growth rate of industrial production and world trade in the following years had been significantly higher than in previous years and periods.

Increased trade with the effect of the industrial revolution has led to the need for trade education. Commercial education, which began with the Industrial Revolution in Europe and the United States, is the foundation of today's major trade schools. In this study, we examined how business education began in Europe and the United States, the steps it took and how it was taught.

Economic growth and development are not the same things, although economic growth is a phenomenon that is followed by almost everyone. Economic growth includes the increase in per capita national income. Development involves both economic growth and structural change. Economic development occurs over a long period of time when there is an increase in the economic welfare of individuals in a country. The idea of a link between development and foreign trade in economic theory is based on classical economists. Adam Smith and David Ricardo, J.S., who were the representatives of the liberal view, who produced their works in the second half of the 18 th century and the first half of the $19^{\text {th }}$ century. Classical economists like Mill talk about the dynamic effects of markets. Not only one country will benefit from free foreign trade, but international prosperity and exchange will increase prosperity all over the world. Since the second half of the $19^{\text {th }}$ century and at the beginning of the $20^{\text {th }}$ century, there has been strong criticism of the views of the Classical School.

The systematic penetration of trade education into the European and American Education Systems, which is the basis of today's Faculties of Business and Economics, has been with the Industrial Revolution. These schools, which constitute the foundations of today's highly respected universities, have given great importance to the merchant sector and they have never denied the material and moral support of these schools both during the establishment and development of these schools. Over time, the educational contents changed, were updated and started to use modern educational techniques required by the era. The main reason for the emergence of these schools was the need for qualified manpower required by the trade. Realizing that economic growth cannot be lasting without economic development, the western world has seen and continued to invest in people who are at the heart of economic growth.

In fact, in our country, trade education has started to be given in a way that does not fall behind the Western examples. The Greek nation, which was the best nation in the Ottoman Empire, established the Elen Commerce School in Heybeliada (Halki), the first private business school of the country, in 1831 and began to train traders in need of trade. Following the closure of the Elen School of Commerce for various reasons, the Hamidiye School of Commerce was established in 1883 as the first public school of the country. After school, it became Istanbul Academy of Economic and Commercial Sciences, and gave life to Marmara University which is today one of the biggest universities in the country. 


\section{Giriş}

Son çeyrek yüzyılda, dünyada yaratılan gelir üç katından, dış ticaret hacmi ise beş katından daha fazla büyümüştür. Dış ticaret hacminin gelire oranı 14 puan artarak yüzde 44'e ulaşmıştır. Neredeyse yaratılan gelirin yarısı kadar ticaret yapılmaktadır. Uluslararası ticaretin ve ekonomik ilişkilerin büyümesini olumlu yönde etkileyen başlıca neden, ülkelerin ticaretin artmasından yararlandıklarını açıkça görmeleridir. Uluslararası siyasi alandaki yumuşama, teknolojik devrimin de katkısıyla haberleşme ve ulaşım alanındaki gelişmeler, piyasa mekanizmasını tercih eden ekonomi politikası yaklaşımı, gelişmekte olan ülkelerin ekonomik işbirliğine katılma istekleri, sermaye hareketlerinin serbestçe dolaşımına yönelik uygulamalar da bu gelişmeyi olumlu yönde desteklemiştir. Bu süreçte, finansal piyasalar hızla büyümüş, dijital teknoloji ile tam anlamıyla entegre olmuş küresel anlamda bir piyasa oluşmuştur (Özince, 2007, s.3).

Ekonomik büyüme hemen hemen herkes tarafından dikkatle izlenen bir olgu olmasına karşılık, ekonomik büyüme ve kalkınma aynı şeyler değildir. Ekonomik büyüme kişi başına düşen ulusal gelirin artışını bünyesinde barındırır. Kalkınma ise hem ekonomik büyüme ve hem de yapısal değişimi ihtiva eder. Ekonomik kalkınma uzun bir zaman sürecinde bir ülkenin bireylerinin ekonomik refahında artı̧̧ olduğu zaman ortaya çıkar. İktisat teorisinde kalkınma ile dış ticaret arasında bir bağ olduğu fikri klasik iktisatçılara dayanır. 18.yy'ın ikinci yarısı ile 19.yy'ın ilk yarısında eserlerini veren ve liberal görüşün temsilcileri olan Adam Smith, David Ricardo, J.S. Mill gibi klasik iktisatçılar piyasaların dinamik etkilerinden bahsederler. Serbest dış ticaretten sadece bir ülke değil bütün ülkeler faydalanacak, uluslararası ihtisaslaşma ve mübadele ile tüm dünyada refah artacaktır. 19. yy’ın ikinci yarısından itibaren ve 20.yy’ın başında Klasik Okulun görüşlerine karşı şiddetli eleştiriler yapıldı. Özellikle azgelişmiş veya geri kalmış ülkelerin diğer gelişmiş ülkelerin rekabetinden korunmak için serbest dış ticaret teorisinin reddi ve korunma politikalarının savunulması söz konusu oldu (Bilgili, 1998, s.35-39).

Sanayi Devrimi ile birlikte zenginleşmenin yolu artık imalat yoluyla üretip serbest ticaret politikaları ve araçları ile dünyaya satmaktan geçiyordu. O zamana kadar dünyanın kıymetli madenlerinin sömürüsü ve uluslararası ticaret yoluyla sağlanan ticari sermaye birikimi yüzyılın ikinci yarısından itibaren imalat üzerinden hedef yükselterek devam etmeye başlamıştı. Nitekim daha sonraki yıllarda dünya sanayi üretiminin ve ticaretinin büyüme hızı önceki yıllara ve dönemlere kıyasla çok daha yüksek düzeylerde gerçekleşmişti. Mesela, 18. yüzyıl boyunca dünya sanayi üretiminin ve ticaretinin yıllık ortalama büyüme hızları sırasıyla yüzde 1,5 ve 1,1 iken; 1780-1830 döneminde yüzde 2,6 ve 1,4; 1820-60 döneminde ise yüzde 3,2 ve 3,8 olarak gerçekleşti (Beaud, 1983, S.17.)

\section{Avrupa'da Ticaret Eğitimi}

Avrupa'da İşletmecilik Okullarının tarihi 2 ayrı dönemde incelenebilir:

a. 1819-1944 Yıllarını kapsayan Kuruluş Dönemi

b. II. Dünya Savaşı Sonrası-Günümüze kadar devam eden Asimilasyon Dönemi

Kuruluş Dönemi: Bu dönemde kurulan okullar 2 farklı model altında incelenebilir. Fransa ve Belçika öncülüğünde Güney Modeli ve Almanya öncülüğ̈̈nde Kuzey Modeli.

\section{Güney Modeli}

\subsection{Fransa'da Ticaret Eğitimi}

Fransa’daki ticaret eğitimi kurulduğu andan 1886 yılına gelinceye kadar 3 grup okuldan oluşmaktaydı:
a. Yüksek Ticaret Okulları
b. Ticaret Okulları

\section{c. Yetişkinler için Ticaret Kursları}

Fransa genelinde ticaret eğitimi bu 3 okulun amaç ve eğitimleri çerçevesinde şekilleniyordu. 


\section{a. Yüksek Ticaret Okulları}

1886 yılında, Fransa genelinde Paris’te 2 adet, taşrada 5 adet olmak üzere toplam 7 adet Yüksek Ticaret Okulu mevcuttu. Bu okulların 1886 yılı öğrenci sayıları ve kuruluş yılları aşağıdaki gibiydi:

\begin{tabular}{|l|c|r|}
\hline \multicolumn{1}{|c|}{ Tablo 1: 1886 Yı̈lı İtibariyle Yüksek Ticaret Okulları ve Öğrenci Sayılar1 } & Kuruluş Tarihi & Öğrenci Sayısı \\
\hline \multicolumn{1}{|c|}{ Yür| } & 1820 & 110 \\
\hline Ecole Supérieure de Commerce de Paris & 1881 & 128 \\
\hline Ecole des Hautes Etudes Commerciales & 1871 & 99 \\
\hline Ecole Supérieure de Rouen & 1872 & 112 \\
\hline Ecole Supérieure de Commerce et de Tissage de Lyon & 1872 & 40 \\
\hline Ecole Supérieure de Commerce de Marseille & 1871 & 111 \\
\hline Ecole Supérieure de Commerce du Havre & 1874 & $\mathbf{6 1 8}$ Öğrenci \\
\hline Ecole Supérieure de Commerce de Bordeaux & Toplam & \\
\hline
\end{tabular}

Kaynak: L'enseignement Commercial et Les Ecoles de Commerce en France et Dans Le Monde Entier". E. Minot, 1887, Journal de la Société Statistique de Paris, 28, sf. 272.

Fransa'nın bu tarihteki nüfusunun 36 milyon olduğu dikkate alındığında, bu oranda bir nüfus içerisinde sadece 618 ticaret öğrencisinin olması yetersiz olarak görülebilir. Aynı tarihlerde Viyana Ticaret Akademisi'nde Fransa toplamından daha fazla öğrenci varken, New York’taki ticaret öğrencisi sayısı Paris’in iki katıydı.

Buna rağmen Fransız Yüksek Ticaret Yüksekokulları'nın ünü yurt dışında çoktan duyulmuştu. Fransız Modeli; Anvers, Venedik, Prag, Leipzig, Varşova ve İstanbul'daki ticaret okulların kuruluşunda “model okul” oldu. Oysa Fransızlar kendi modellerinin örnek alınmasını “kendilerini vurmaları için düşmanlarına silah vermek” olarak görüyorlardı (Minot, 1887, Sf. 272).

1819 Yılında tüccar Vital Roux ve ekonomist Jean-Baptiste Say beraberce dünyanın ilk ticaret okulunu kurdular. Okulun öncülerinden Jacques Lafitte; 1807 yılında yapılan Fransız Ticaret Kanunu'na katkı sağlayan bir yazar ve okulun kurucu ortağı idi. Ekonomist Jean Baptiste Say ise bu türden bir okul konseptinin mucidiydi.

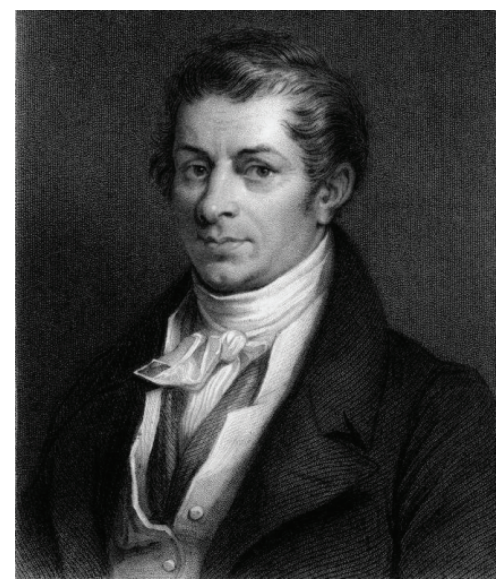

Resim 1: Jean-Baptiste Say (05.Ocak.1767-15.Kasım.1832)

Fransiz Ekonomist

1869-1969 yılları arasında Paris Ticaret ve Sanayi Odası himayesinde okul daha güçlü bir yapıya kavuştu ve olgunluğa ulaştı. Paris Ticaret ve Sanayi Odası sayesinde hem sektörel ihtiyaçları karşılama esnekliği hem de programların 
uygulanabilirliği arttı. Bu yeni işbirliğinin kazandırdığı ivme sayesinde okulun hem programları genişledi hem de okula kaydolan öğrenci sayısında artış oldu. 1820'lerde birkaç düzine öğrenciden, 19. yüzyılın sonunda 250’ye kadar artan öğrenci sayısı 1970’li yıllara gelindiğinde artık binlerle ifade edilmeye başlandı. Günümüzde Berlin, Londra, Paris, Madrid ve Torino'da İşletmecilik Eğitimi veren kampüslere sahip çok itibarlı bir işletmecilik okulu haline geldi.

Okulun geçirdiği evrim ve bölümlerdeki artış aşağıdaki gibi özetlenebilir:

a. 1890'da eğitimin devlet tarafından tanınması.

b. İlk ihtisas bölümlerinin kurulması: Okulun ilk yıllarında açılan Dış Ticaret Acentacılığı Bölümü - Denizcilik bölümü (1905), Sömürge Bölümü (1913), Otelcilik Bölümü (1916), Ticaret Temsilciliği Bölümü (1917)

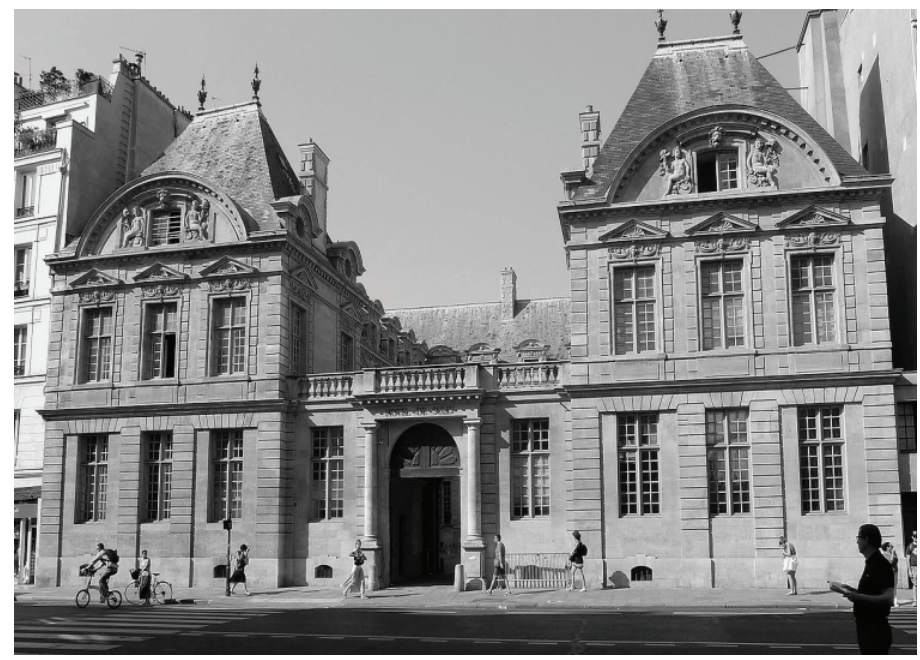

Resim 2: Ecole Commerciale de Paris - Paris IV rue St-Antoine hotel de Sully

\begin{tabular}{|l|c|}
\hline \multicolumn{1}{|c|}{ Tablo 2: Fransa'da Tanınmış Bazı Yüksek Ticaret Okulları “Ecoles Supérieurs de Commerce (ESC)" } & Kuruluş Tarihi \\
\hline \multicolumn{1}{|c|}{ Yüksek Bilinirliğe Sahip Olunanlar } & 1819 \\
\hline \multicolumn{1}{|c|}{ Diğerleri } & 1881 \\
\hline \multicolumn{1}{|c|}{ ESCP-EAP (ESC Paris) } & 1907 \\
\hline HEC-Hautes Etudes Commerciales & 1871 \\
\hline ESSEC-Ecole Supérieure des Sciences Economiques et Commerciales & 1871 \\
\hline & 1872 \\
\hline ESC Rouen & 1872 \\
\hline Ecole de Management de Normandie (ESC Le Havre) & 1874 \\
\hline Ecole de Management de Lyon (ESC Lyon) & 1892 \\
\hline Euromed (ESC Marseille) & 1897 \\
\hline Bordeaux Management School (ESC Bordeaux) & 1900 \\
\hline ESC Lille & 1900 \\
\hline ESC Montpellier & 1912 \\
\hline ESC Dijon & 1919 \\
\hline Audencia (ESC Nantes) & \\
\hline ESC Toulouse & \\
\hline ESC Clermont & \\
\hline $\begin{array}{l}\text { Kaynak: “From “Ecoles Supérieures de Commerce” to “Management Schools” M. Blanchard, 2009, Transformations and Continuity in French Business } \\
\text { Schools, European Journal of Education, 44(4), sf. 588. }\end{array}$ \\
\hline
\end{tabular}




\section{a. Ticaret Okulları}

1886 yılı itibariyle Ticaret Okulları toplamda 4 adet olup, kuruluş tarihleri ve anılan yıl itibariyle öğrenci sayıları aşağıdaki gibiydi:

\begin{tabular}{|l|c|c|}
\hline \multicolumn{1}{|c|}{ Tablo 3: 1886 Y1lı İtibariyle Ticaret Okulları ve Öğrenci Sayıları } & Kuruluş Tarihi & Öğrenci Sayısı \\
\hline \multicolumn{1}{|c|}{ Trarı } & 1863 & 500 \\
\hline Ecole Commerciale de l'avenue Trudaine & 1884 & 131 \\
\hline Institut Commerciale de la Chaussée d'Antin & 1871 & 18 \\
\hline Ecole Supérieure de Rouen & 1850 & 245 \\
\hline Ecole Pratique de Commerce et de Comptabilité & 1875 & 23 \\
\hline Ecole Municipale de Reims & Toplam & $\mathbf{8 9 9}$ Öğrenci \\
\hline \multicolumn{2}{|c|}{$\begin{array}{l}\text { Kaynak: “L'enseignement Commercial et Les Ecoles de Commerce en France et Dans Le Monde Entier”. E. Minot, 1887, Journal de la Société } \\
\text { Statistique de Paris, 28, sf. 273. }\end{array}$}
\end{tabular}

Ecole Commerciale de l'Avenue Trudaine; tıpkı Ecole Supérieure de Commerce de Paris gibi Paris Ticaret Odası'na aitti. Paris ticareti için mükemmel bir işçi havuzuydu. Ticaret okulunun programı 5 yıllık bir eğitim programını kapsıyordu. Yetişkinler için dersler gece yapılırken, okulun nüfusu bu şekildeki bir eğitim programıyla kadın ve erkeklerden oluşan yaklaşık 1200 kişiye ulaşıyordu. Paris Ticaret Okulu bu okulun varlığından büyük gurur duyuyordu (Minot, 1887, sf. 273).

L'institut Commerciale de la Chaussée d'Antin; öğrenim süresi 3 yıl olan bu okulun amac1 gençleri ihracata yönelik olarak hazırlamaktı. Fransa'da bu yıllarda dış ticaret genellikle yabancı komisyoncuların elindeydi. Okulun amacı da yabancıların elinde olan bu alana Fransız gençlerini yavaş yavaş istihdam ederek yabancıların egemenliğini ortadan kaldırmaktı. Bu amaçla diğer okullara nazaran daha uygulamaya yönelik, pratik eğitim veriliyordu (Minot, 1887, sf. 273).

L'Ecole Pratique de Commerce et de Comptabilité; Rahip Pigier tarafından kurulan bu okulda öğrenim süresi 3 ila 6 ay arasında değişiyordu. Öğrenciler burada sanal ticaret ile değil doğrudan reel (gerçek) ticaret ile eğitiliyorlardı. Gerçek ticarete dayalı bu ticaret okulu ailelerin ve tüccarların gözdesiydi. Okulun kurucusu Rahip Pigier hiçbir yardım almaksızın, Paris’in göbeğinde, Rivoli Caddesi’nde, mükemmel bir lokasyonda, halkın yeni öğretim modelini bizzat görebildiği bir okulu hayata geçirmeyi başardı (Minot, 1887, sf. 273).

L'Ecole Municipale de Reims; Ticaret Okulları arasında değerlendirilen son okul olan Reims Belediye Okulu'nda, tek seferde tarım, ticaret ve sanayi eğitimi veriliyordu. Okul hem kendi bölgesine hem de büyük şehirlerin belediyelerine hizmet vermekteydi (Minot, 1887, sf. 273).

\section{b. Yetişkinler için Ticaret Kursları}

Üçüncü ve son okul grubunda değerlendirilen bu ticari kurslar yetişkin kadın ve erkekler içindi. 1886 yılı itibariyle Ticaret Kursları'nın kadın ve öğrenci sayıları aşağıdaki gibiydi: 


\begin{tabular}{|c|c|c|}
\hline Ticaret Kursları & Erkek Öğrenci & Kadın Öğrenci \\
\hline Association Philotechnique & 1.260 & 629 \\
\hline Ecole Elisa Lemonnier & - & 132 \\
\hline Cours du Grand-Orient de France & 634 & 316 \\
\hline Société pour L'instruction Elémentaire & - & 157 \\
\hline Ecole Commerciale de l'avenue Trudaine & 1.000 & 200 \\
\hline Cours Commerciaux de la Ville de Paris & 688 & 671 \\
\hline Cours d'Etudes Commerciales (Fondation Bamberger) & 492 & - \\
\hline Cours de L'Union Nationale & 480 & 235 \\
\hline Cours du $1^{\text {er }}$ Arrondissement & 110 & 45 \\
\hline Caisse des Ecoles du $8^{\mathrm{e}}$ Arrondissement & 50 & - \\
\hline Institut Polyglotte & 300 & 93 \\
\hline Société Pour L'étude des Langues Etrangères & 710 & - \\
\hline Société Académique de Comptabilité & 355 & - \\
\hline Chambre Syndicale des Comptables & 100 & - \\
\hline Toplam & 6.179 Erkek & 2.478 Kadın \\
\hline
\end{tabular}

\subsection{Belçika'da Ticaret Eğitimi}

Belçika Hükümeti ticaret eğitimini « Athénée » adı verilen ve serbest meslek ve profesyonel diğer kariyerlere hazırlayan orta kademe okulların programlarına almıştı. Athénée’ler Belçika’nın ve yabancı ülkelerin ürünlerinden örnekleri bünyesinde barındıran bir müze gibiydiler. Bu okulların öğrenci nüfusu yaklaşık 24.000 kişiydi. Öğrencilere profesyonel orta öğretim sertifikası veriliyordu. Yüksek ticaret eğitimi almak isteyen okullara kaydolmak isteyen öğrenciler Institut Supérieure de Commerce d'Anvers'e kayıt yaptırıyordu. Enstitü’nün kuruluş tarihi 1853 olup, 1886 yılına kadar 3.297 öğrenci okula kaydolmuştu. Bu öğrencilerden 1.905'i Belçikalı iken, 1.392'si yabancı öğrenciydi.

Belçika'da ticaret eğitimine ilişkin dikkat çeken bir diğer okul ise kuruluş tarihi 1852 olan Antwerp’teki Yüksek Ticaret Enstitüsü'dür. Okulda sunulan program ESCP Fransa kapsamında olup coğrafya, tarih ve yabancı diller de programa dahildi. Özel teşebbüs tarafından finanse edilen ESCP Fransa okulundan farklı olarak Antwerp Enstitüsü devletin sahipliğindeki bir okul olup üniversite özelliklerine sahipti (Kaplan, 2014, sf. 530) .

Avrupa'da kurulan hemen hemen tüm ticaret okullarına iki okul ilham kaynağı oldu: L'Ecole Supérieure de Commerce de Paris ve L'Institut d'Anvers (Minot, 1887, sf. 275-278).

Bu nedenle Güney Modeli kendi içerisinde tutarlı, pratik ticaret eğitimin verilmesine öncü bir model olarak değerlendirilebilir. Ancak Almanlar bu modelin eksiklikleri üzerine kendi modellerini oluşturmayı ve ticaret eğitiminde bunu uygulamayı daha doğru buldular. Bu model "Modern İşletmecilik” eğitimine geçilmesine de öncü oldu.

\section{$\underline{\text { Kuzev Modeli }}$}

\subsection{Almanya'da Ticaret Eğitimi}

İlk Alman ticaret okulları Fransa'daki ticaret okullarından birkaç on yıl sonra kuruldu. Alman ticaret okulları özellikle Kuzey Avrupa Okulları için birer model teşkil ettiler. Almanya’nın ilk işletmecilik okulu 1898 yılında Leipzig Ticaret Odası'nın inisiyatifleri ile kurulmuş olan Handelshochschule'dir (Kaplan, 2014, sf. 530). 


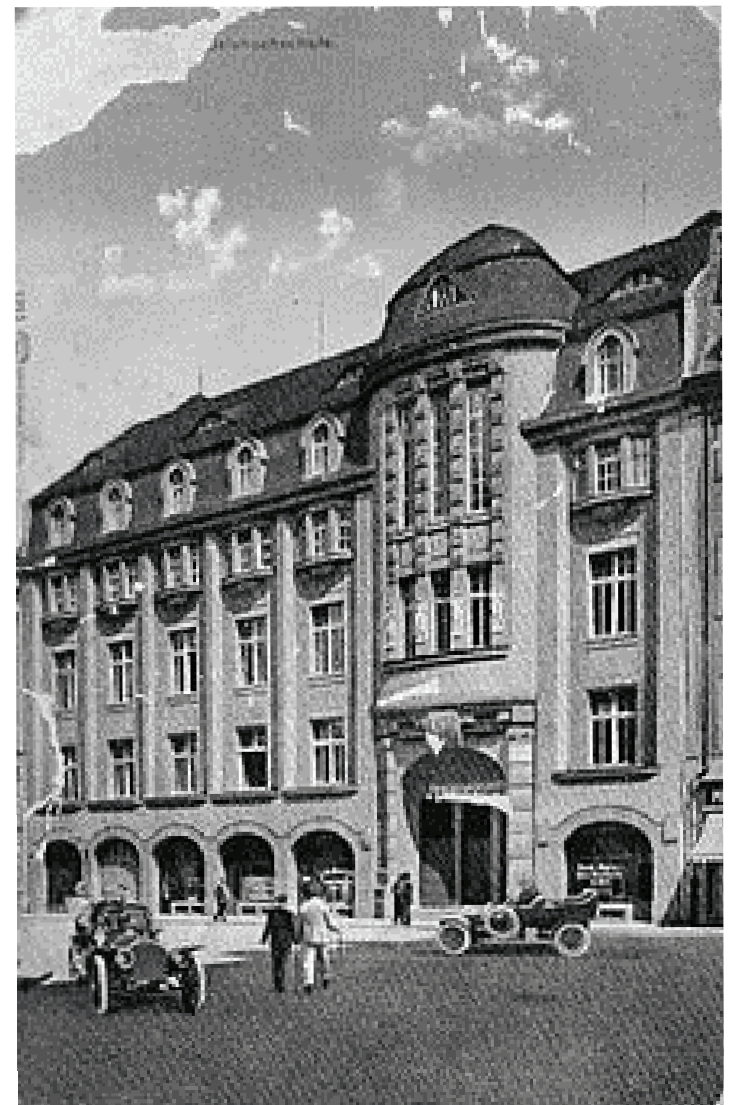

Resim 3: Handelshochschule Leipzig-1911

Okulda bir ticaret okulunda verilmesi gereken temel derslerin yanında iktisat, hukuk, coğrafya, emtia ve mal ticareti, bilim ve teknoloji, ticari teknikler ve beşeri bilimler gibi disiplinler arası dersler okutulurken, diğer yanda teorik ve pratik unsurlardan oluşan bir yabancı dil eğitimi de veriliyordu. Alman ticaret okulları, yönetimin sadece uygulamada öğrenilebileceğine inanların üstesinden gelmeye çalışıyordu. Fransız ticaret okulları tamamen teorik yapıdaki işletmecilik eğitimine karşı dururken, Alman ticaret okulları hızlı bir şekilde işletmecilik eğitimini akademik bir yapıya oturtmaya çalıştılar. Bu yeni uygulama yeni bir akademik alana yol açtı: İ̧̧letme Yönetimi Bilimi. Humbold'un bilim yoluyla eğitim geleneği Almanya'da hızlıca kök saldı. Bu gelenek eğitsel ve bilimsel faaliyetler arasındaki ayrımı tamamıyla reddediyordu. Önde gelen akademisyen ve ekonomist Eugen Schmalenbach, 1900'lü yıllarda yoğun bir şekilde bir okulun amacının bireyin kârını artırmaktan ziyade genelin refahını maksimize etmek olduğu konusunda ısrar ediyordu. Scmalenbach'ın çabalarıyla "yönetim" daha önceleri devlet üniversiteleri tarafından reddedilmesine karşılık bir akademik disiplin olarak kabul edildi. 1910'lu yıllarda bir çok Alman işletmecilik ve ticaret okulu kamu üniversitelerine entegre edildi (Kaplan, 2014, sf. 530).

Handelshochschule Leipzig in haftalık ders programı aşağıda gözüktüğü gibiydi. Öğrenciler 3 yıllık ticaret yükseköğreniminde ilk yıl 36 saat ikinci yıl 35 saat üçüncü yıl ise yine 36 saat boyunca sadece ticaret dersleri değil, aynı zamanda fizik ve kimya gibi analitik düşünmeye yardımcı temel bilimleri de alıyorlardı. Kuvvetli dil eğitimi isteğe bağlı olarak seçilen İtalyanca ile daha da perçinleniyordu. Burada gördüğümüz ders planını akılda iyi tutmakta fayda var. İleride bizim "Elen Ticaret Okulu” nun ders planını incelerken bakalım ne kadar tanıdık gelecek? 
Tablo 4: Handelshochschule Leipzig Haftalık Ders Programı

\begin{tabular}{|c|c|c|c|}
\hline Dersler & 1.ci Yll & 2.ci Yll & 3.cü Yıl \\
\hline Almanca & 4 & 3 & 3 \\
\hline İngilizce & 5 & 4 & 3 \\
\hline Fransizca & 5 & 4 & 3 \\
\hline Matematik & 3 & 3 & 3 \\
\hline Ticari Matematik & 5 & 3 & 2 \\
\hline Fizik & 3 & 2 & - \\
\hline Teknoloji & - & - & 2 \\
\hline Kimya & - & 2 & 2 \\
\hline Emtia Öğrenimi & - & - & 1 \\
\hline Coğrafya & 2 & 2 & 2 \\
\hline Tarih & 2 & 2 & 2 \\
\hline Ticari Bilimler & - & 2 & 2 \\
\hline Sayım Odası İşlemleri & - & 2 & - \\
\hline İletişim-Ticari Yazışma & - & - & 2 \\
\hline Defter Tutma & - & - & 2 \\
\hline Politik Ekonomi & - & - & 2 \\
\hline Kaligrafi-Güzel Yazı Sanatı & 3 & 2 & 2 \\
\hline Çizim & 2 & 2 & - \\
\hline Jimnastik & 2 & 2 & - \\
\hline Haftalık Ders Saati & 36 & 35 & 36 \\
\hline \multicolumn{4}{|l|}{ Zorunlu Olmayan Dersler } \\
\hline İtalyanca & - & 2 & 2 \\
\hline Stenografi & 2 & 1 & 1 \\
\hline
\end{tabular}

Alman Ticaret Okulları'nın işletmecilik alanındaki başarısı neticesinde 19 Yüzyılın sonunda şu soru sıkça sorulmaya başland1 ( Chatziioannou ve Tsilaga, 2015, sf. 222) Alman Ulusunun ticari başarısı verdikleri ticaret eğitimin bir sonucu muydu? Yoksa Almanların ticari gelişmesi nedeniyle mi ticaret eğitimi başarılı bir işletmecilik eğitimine dönüşmüş̧ü? Kanaatimce bu soru bugün bile hala üzerinde tartışılması gereken bir konu olarak tartışılmaya muhtaç.

\subsection{Avusturya'da ticaret eğitimi}

Alman ekolünün devamı olan Avusturya'da da dikkat çeken ticaret okulları mevcuttu. Bunlar arasında en önemlisi, kuruluşu 1857 yılına dayanan "Viyana Handelsakademie" dir. 2 yıllık kesintisiz eğitimin ilk yılı genel aritmetik, fiziki coğrafya, doğa tarihi, zooloji, maden bilimi, botanik, güzel yazı sanatı (kaligrafi), ilk derece defter tutma (temel muhasebe), yakın devletlerin yabancı dilleri derslerini kapsıyordu. Okulun ikinci yılında ise öğrenci, ileri muhasebe (karmaşık defter tutma düzeni), ileri aritmetik (karmaşık aritmetik), dış ticaret işlemleri, ticari coğrafya, uluslararası politik ve ticari ilişkiler, politik ekonomi, para sayım odası uygulamaları, teknoloji ve ticari varlıkların pratik analizi derslerini alıyordu. Derslerin genel kapsamından, okulda verilen eğitimin amacının tecrübeyi uzmanlaşma ile bütünleştirmek olduğu anlaşılmaktadır (Holdges, 1887, sf.462-470; Tsilaga, 2015, sf. 221-222) 


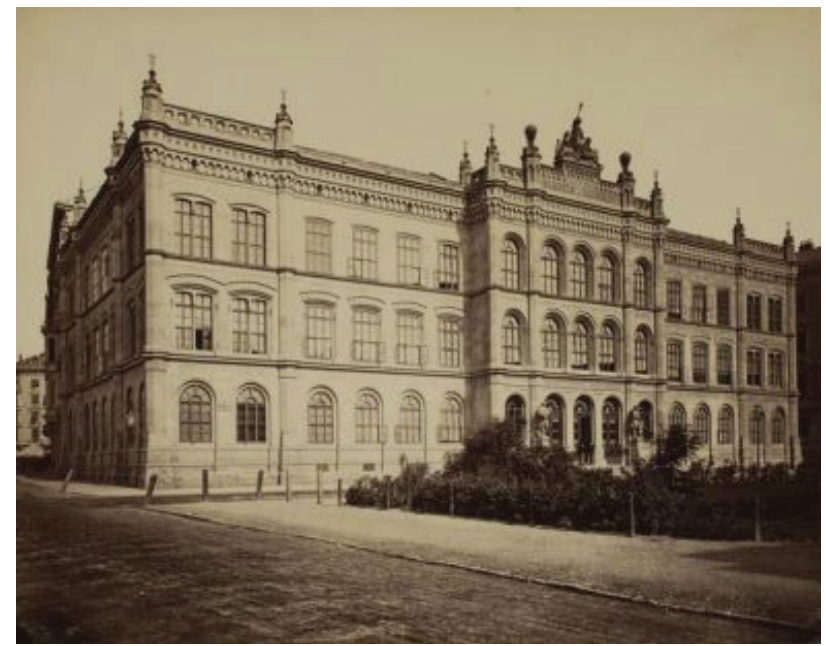

Resim 4: Handelsakademie Wien-1865

\section{5. İngiltere'de Ticaret Eğitimi}

İngiltere'de ticaret eğitimi Almanların bu konudaki fikirlerinden etkilenmiş ancak bazı hususlarda bağımsız bir yapıdadır. Almanya ve İngiltere ticaret eğitimini temelde karşılaştırmak gerekirse; ilk dönemlerde Alman ticaret eğitiminin İngiliz ticaret eğitimine göre açık ara daha gelişmiş olması şaşırtıcı değildir. Almanya'da ticaret okulu öğretmenleri çok daha iyi örgütlenmişti. Bu örgütlenmeden anlaşılması gereken karşılıklı olarak birbirlerinin tecrübelerini paylaşmanın yarattığı itici güçtü aslında. Alman ticaret öğretmenleri kendi aralarında eğitim tecrübelerini paylaşıyorlardı. Ticaret Öğretmenleri Birliği'nin dergisi Zeitschrift für das gesamte Kaufmännische Unterrichtswese’ ne yazı, makale ve görüşlerini yazarak dünyanın pek çok ülkesinden katkı sağlayan öğretmenler vardı (Heining, 1902, sf. 125)

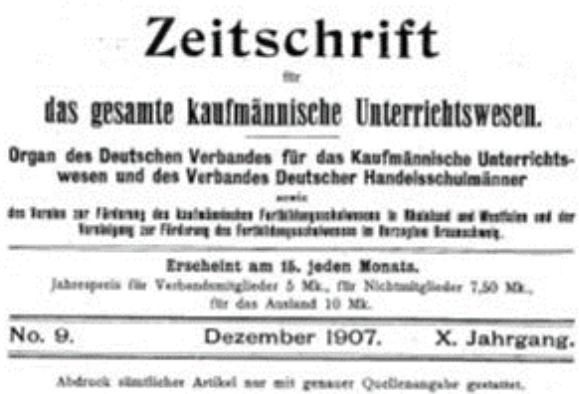

\section{Allgemeiner Teil.}

Zur Geschichte der Handelshochschulen.

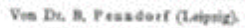

Die bodeutungsvolle Organisationstrage bel Errichtung einer Handelabochachule, ob selbutandige oder angegliederte Aatealt, ist worden. Hatte doch Marberger bereits 1713 uad 1723 die Errichtung einer oKauflmanns-Akademiev yorgecchlagen, war fernet in Leiptig 1728 der Gedanke aufgetaucht, dort ein. Seminarium Scientarum Mercaturae Publicum, zu emichten oder (um 1750) eigene Professoren der , Handiungswissenschaft. as der Uinivensita ant Tape cristage getreten,

Der im Jahre 1862 ins Leben gerretenen Handeb- und Ge. werbekammer Dresden lag bereits im Jahre 1863 ein Antrag auf Errichtung einer Profetur der Habdelswissenschaft an der Uni. versitit wot, det nur deshalb far die Zukunit ausgeietzt worden

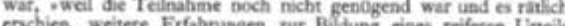
encticen, wetere

Zu pleicher Zeit beachstrigten sich die alchuinchen Handel. xchulen mit dieser Frage. Sie schienen 1863 auf einem Punkte angelangt $z u$
Dienste und in ihr ferneres Bestehes ene strenge Kritik der

Resim 5: Zeitschrift für das gesamte Kaufmännische Unterrichtswesen 
Oysa bu dönemde İngiltere'de ne Ticaret Öğretmenleri Birliği mevcuttu ne de öğretmenlerin bilgi ve tecrübe paylaşımında bulunabilecekleri böyle bir dergileri vardı. Alman ve İngiliz ticaret eğitimi yapılarındaki temel farklılıklardan birisi de 14 yaşında okuldan ayrılıp bir işyerinde çalışmaya başlayan çocuğun eğitiminde ortaya çıkan farklılıktı. Almanya'nın birçok yerinde, bu şekildeki çocukların (gençlerin) eğitimi zorunlu iken, İngiltere'de isteğe bağlıydı. Almanya'da eğitim gündüz verilirken, İngiltere'de ticaret eğitimi gece veriliyordu. İngiltere'de Gece Ticaret Okulları daha çok Okul Kurulları tarafından işletiliyordu. Gece Okulları'nın varlığı konusu o dönemde ciddi bir tartışma konusuydu. Gece Okulları’nda verilen dersler ya ücretsiz ya da bazıları çok düşük fiyatlarlaydı. Okul kurulları seçimi tamamıyla temel eğitimin amacına göre gerçekleşiyordu. Okulların ücretsiz olmasının sebebi, bir hukuk mahkemesinin verdiği karara dayanmaktaydı. Bu karara göre; “vergi mükelleflerinin ödedikleri paranın yükseköğrenim amacıyla harcanması yasa dışı” olarak kabul edilmişti (Heining, 1902, sf. 126).

İngiltere 1899 ve 1900 yıllarında Londra Okul Kurulu’nun devamlılı̆ııı sağladı. İngiltere'de 12 Akşam Ticaret Okulu vard1. 350 kişilik öğrenci grubuna Defter Tutma, Stenografi ve Fransızca öğretiliyordu. Aynı akademik yılda 9.217 öğrenci Gece Ticaret Okullarına kaydolmuştu. Bu öğrencilerden 25 i 14 yaşında iken, 5.540 kişisi 14-21 yaş arasında, 3.652 kişisi de 21 yaş üstündeydi (Heining, 1902, sf. 126).

Sonraki yıllarda Londra Ticaret Odası Fransız ve Alman Ticaret Eğitimi Modelleri çerçevesinde bir program oluşturdu. Buna göre 6. sınıfı bitiren bir öğrenci zorunlu derslerden ve en az bir seçimlik dersten sınava giriyordu. Buna göre;

Zorunlu Dersler: İngilizce ve İngiliz Edebiyatı-Fransızca (zamanla Almanca, İspanyolca, İtalyanca ve Portekizce)İngiltere’nin ve kolonilerinin ticari tarihi-ticari coğrafya-aritmetik-defter tutma-çizim

Seçimlik Dersler: Doğa Bilimlerinin Değişik Branşları- Coğrafi Çizim-Stenografi-Latince

Bu bölümleri başarıyla bitiren öğrenci yüksek sınıflara kabul ediliyordu. Bu kez yüksek sınıflarda öğrencinin;

Zorunlu Dersler: İki Yabancı Dil-Matematik-Ticari Coğrafya-Evrensel ve Ticari Tarih- Politik Ekonomi- BankacılıkSigorta İşlemleri-Ticaret Hukuku-Fabrika Hukuku (İş ve Sosyal Güvenlik Hukuku anlamında)

Sınava girip başarılı olan öğrenciye "Yüksek Ticaret Sertifikası" veriliyordu.

Bunların dışında bir de diğer ülkelerde pek görülmeyen ancak İngiltere'de uzun müddet popülerliğini korumuş olan "Evde Özel Ticaret Eğitimi” alanı vardı. Özel Ticaret Eğitimleri, öğretmenlerin ya kendi evlerinde, ya evin müştemilatında ya da öğrencinin ikametgâhında veriliyordu. Özel dersler, üst gelir grubu ebeveynlerin kendi çocukları için tercih ettiği bir yöntemdi. Öğretmenler belirli aralıklarla ya da sürekli olarak kendi evine-öğrencinin ikametgâhına gidiyordu. Aileler ihtiyaç duyduğunda öğretmen tam zamanlı bir eğitimi verebiliyordu. Matematik alanında akademi tabanlı birkaç öğretmen, öğretmenlik kariyerlerine bu şekilde başladı. Muhasebe konusunda da aynı durum söz konusuydu. Dönemin en ünlü defter tutma öğretmenleri arasında anılan Benjamin Donn, Thomas Crosby ve Charles Hutton da ilk kariyerlerine "özel öğretmen" olarak başladılar (Edwards, 2011, sf. 46). 


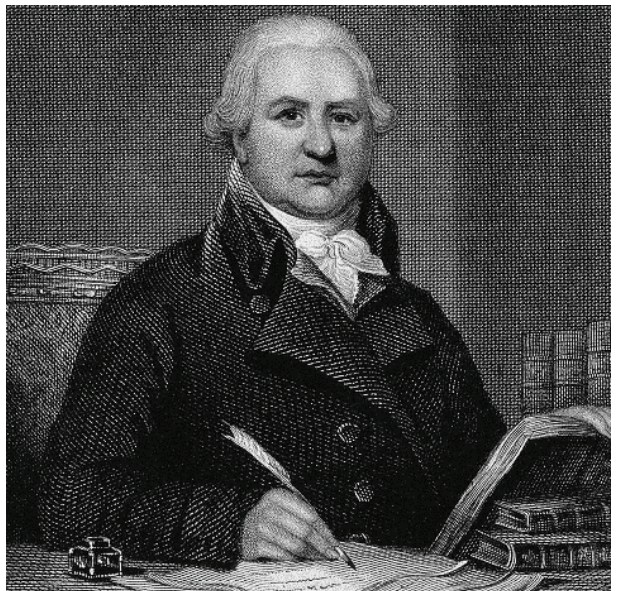

Resim 6: Charles Hutton (4 Ağustos 1737-27 Ocak 1823)

İngiliz Matematikçi

\section{Amerika Birleşik Devletleri’nde ticaret eğitimi}

Amerika Birleşik Devletleri’nde 1800'lü yıllarda sivil inisiyatiflerle ticaret eğitiminin başladığını görüyoruz. ABD’deki ilk ticaret okulu Wharton Finans ve Ticaret Okulu iken New York Şehri Ticaret Okulu öncü ticaret okullarından birisiydi. Amerikan Ticaret Okulları, Avrupa Ticaret Okulları gibi uluslararası bir yapıya sahip değildi.

\subsection{Wharton Finans ve Ticaret Okulu}

Wharton Finans ve Ticaret Okulu, 1881 yılında kuruldu. Joseph Wharton okulun kurulması için 100.000 USD bağışta bulundu. Wharton için Adam Smith ilham kaynağı olmuştu ve Wharton Taylorizm'den de çok etkilenmişti. Wharton özellikle Taylor'un iş gücü verimliliğini artırmaya yönelik çalışmalarına hayranlık duyuyordu (Kaplan, 2014, sf. 530).

Okulun kurulmasındaki en temel etken kurucu Joseph Wharton’un ileri görüşü ve liberal düşüncesiydi.

Bu düşünce 2 ana temele dayanmaktaydı (McCrea,1913, sf. 111-116):

a. Başarılı Sivil Yönetimi esas alan ilkeler ışığında eğitim

b. İş hayatında tutunmak ve sahip oldukları varlıkların yönetimini üstlenmek isteyenlere uygun bir eğitim

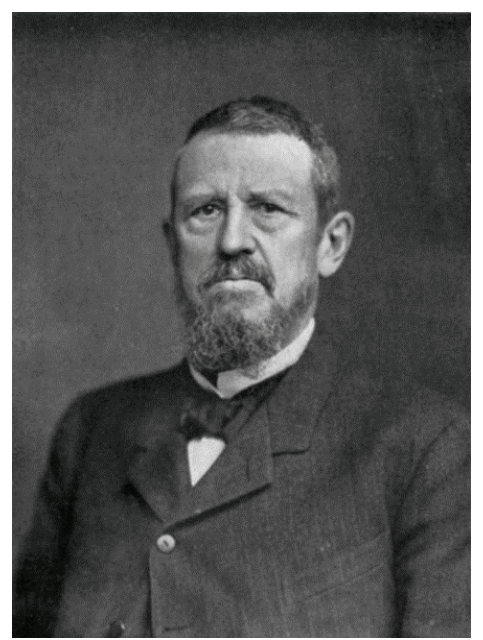

Resim 7: Joseph Wharton (3 Mart 1826-11 Ocak 1909) Amerikan Sanayici ve Girişimci 
Dersler bu ideallere ulaşmak için tasarlandı. İlk önce ekonomik ve politik konuları esas alan konularla işe başlandı. Sonrasında dersler, daha geniş ve farklı birçok alana yayıldı. Bu genel konuların yanında muhasebe, işletme hukuku, özel ve kamu finansı, ticaret, ekonomik kaynaklar, endüstriyel örgütlenme, brokerlik, sigorta ve satış elemanı konuları geliştirildi ve müfredata eklendi. Bundan sonraki amaç bu konuları daha da geliştirmek ve çok daha teknik hale getirmek olarak planland1.

1894 yılından önce, 2 yıllık ders programının ilk yılında, 4 yıllık kolej derslerinin ilk 2 yılında okutulan dersler veriliyordu. İlk 2 yılda genellikle sanatsal konular ders olarak okutuluyordu. 1894 yılında, okul 4 yıllık hale geldi. Yapılan bu yeni düzenlemenin sağladığı rahatlıkla, ticaret dersleri önceki eğitim konularıyla yan yana getirildi. Böylece bu yeni düzenleme öğrencilere öncelikle mesleki eğitim verilmesine, akabinde hemen üniversite derslerini almaya imkân tanıdı. Yani meslek yüksekokulu tarzında bir mesleki eğitim biter bitmez, öğrenci üniversite eğitiminde görmesi gereken dersleri görüyordu.

Wharton Okuluna kayıt, standart bir üniversiteye giriş şartlarını karşılamayı gerektiriyordu. 14 ve $1 / 2$ Carnegie Birimi’nin ( $1 / 2$ Carnegie Birimi, bir tam ders yılının yarısına tekabül eder) alınmış olması gerekliydi. Bu dersler İngilizce, Tarih, Matematik (Cebir ve Düzlem Geometrisi Dâhil), en az 2 yıl İngilizce dışında herhangi bir yabancı dilde ders almış olmak ve 6 birim seçimlik dersleri kapsıyordu. 6 seçimlik dersin İse Fizik Bilimleri, Ekonomi, Ticari Coğrafya, Fiziki Coğrafya ve benzer türden dersler arasından seçilmiş olması gerekiyordu.

Wharton Okulu'ndan mezun olmak için 70 birim krediyi tamamlamış olma şartı vardı. 70 krediden 6 kredi İngilizce, 5 kredi Tarih, 6 kredi Modern Diller kredisi olmak zorundaydı. Kalan krediler için ise, 8 kredinin mutlaka Ekonomi, Politika ve Sosyoloji dışındaki genel üniversite derslerinden birisi olması gerekiyordu. Okulun 3. Yılı tamamlanmadan önce 2 kredi Sosyoloji ve buna ilaveten 2 kredi Politik Bilimler derslerinin de mutlaka alınmış olması şartı vardı. Bu düzenlemelerin neticesinde, düzenli bir şekilde okulda 4 yıl eğitim almış bir öğrenci en az bir tam ders yılına tekabül edecek şekilde teknik konular dışındaki dersleri de almış oluyordu.

Wharton Okulu'ndaki ilk yılda (1.sınıf), İşletme Hukuku, Muhasebe, Ekonomik Coğrafya ve Politik Bilimler, sonraki yıllarda işlenecek daha teknik konulara giriş için bir basamak olsun diye okutulurdu.

Tablo 5: Wharton Finans ve Ticaret Okulu, 1909-1913 Arası Öğrenci Sayıları

\begin{tabular}{|l|l|l|l|l|l|}
\hline & 1. Sinif & 2. Sinif & 3. Sinif & 4. Sinif & Toplam \\
\hline $1909-1910$ & 180 & 102 & 64 & 66 & 482 \\
\hline $1910-1911$ & 235 & 111 & 72 & 71 & 528 \\
\hline $1911-1912$ & 233 & 145 & 67 & 63 & 535 \\
\hline $1912-1913$ & 292 & 136 & 91 & 60 & 636 \\
\hline Kaynak: "Th
\end{tabular}

Kaynak: "The Work of the Wharton School of Finance and Commerce". R. C. McCrea, 1913, Journal of Political Economy, 21(2), sf.111-116.

Wharton Okulu’nda 2. sınıf sonrası öğrenci sayısındaki düşüşün temel sebebi, okulun ilk iki yılında ara kademe için öğrenci yetiştirmesinden kaynaklanmaktaydı. İlk iki yılı bitiren öğrenciler meslek yüksekokulunu bitirmişs sayıldıkları için doğrudan ticaret hayatına atılabiliyorlardı. Ancak üniversiteye devam edip, üniversite mezunu olmak isteyenler, 3. ve 4. sınıfa devam ettiği için, sayının 3. ve 4. sınıfta, ilk 2 yıla göre daha az olduğu görülmektedir. 


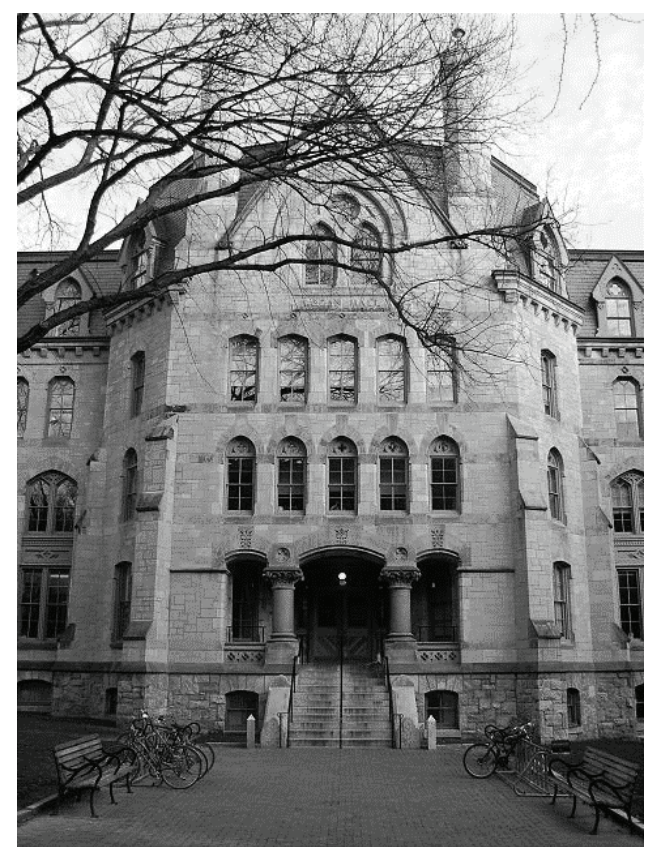

Resim 8: Wharton School of Finance and Commerce

Wharton Finans ve Ticaret Okulu bugün hala ABD'nin en prestijli ticaret okullarından birisidir. Bu okuldan mezun olmuş bazı önemli kişilerin listesi aşağıda yer almaktadır. Okulun mezunlarına burada yer vermemim en önemli nedeni gençlere ilham kaynağı olması içindir. ABD söz konusu olunca mezun listesine ulaşmak diğer ülkelere göre daha kolay oluyor:

\begin{tabular}{|c|c|c|c|}
\hline & Ünlü Kişi & Görevi & İşletme \\
\hline 1 & Aditya Mittal & Başkan ve CFO & Mittal Steel Company \\
\hline 2 & Alex Gorsky & CEO & Johnson \& Johnson \\
\hline 3 & Alfred Berkeley & $\begin{array}{c}\text { Önceki Başkan ve Yönetim Kurulu Başkan } \\
\text { Yardımcısı }\end{array}$ & NASDAQ Stock Market \\
\hline 4 & Anil Ambani, & YKB & Reliance Group \\
\hline 5 & Anthony Connelly & Başkan ve CEO & Disney Cruise Line \\
\hline 6 & Arthur D. Collins Jr. & YKB ve CEO & Medtronic \\
\hline 7 & Ayman Asfari İngiliz-Suriyeli Milyarder & CEO & Petrofac \\
\hline 8 & Beth Axelrod & $\begin{array}{c}\text { "Çalışanların Tecrübesi”"nden Sorumlu } \\
\text { Şimdiki Başkan Yardımcısı }\end{array}$ & Airbnb \\
\hline 9 & Boediono & Guvernör - Bank Indonesia & Central Bank of Indonesia \\
\hline 10 & C. Robert Henrikson & YKB ve CEO & MetLife \\
\hline 11 & Dawn Fitzpatrick & Hisse Senetleri Küresel Başkanı & UBS Asset Management \\
\hline 12 & Dominique Heriard Dubreuil & CEO & Rémy Cointreau \\
\hline 13 & Donald Trump Jr. & Başkan Yardımcısı & Trump Organization \\
\hline 14 & Donny Deutsch & YKB ve CEO & Deutsch Inc. ve DHL \\
\hline 15 & Edmund T. Pratt Jr & CEO ve YKB (Onursal) & Pfizer \\
\hline 16 & Elon Musk & Kurucusu ve CEO & PayPal, Tesla Motors ve SpaceX \\
\hline 17 & Gary L. Wilson & YKB ve CEO & Northwest Airlines \\
\hline 18 & Harold W. McGraw III & YKB ve CEO & McGraw-Hil \\
\hline 19 & Ivanka Trump & Başkan Yardımcısı & Trump Organization \\
\hline 20 & John L. Flannery & YKB ve CEO & General Electric Company \\
\hline
\end{tabular}




\begin{tabular}{|c|c|c|c|}
\hline 21 & John Neff & YKB & Wellington Management \\
\hline 22 & Julian A. Brodsky & Kurucusu, YKB ve CEO & Comcast Corporation \\
\hline 23 & Klaus Zumwinkel & Önceki YKB ve CEO & Deutsche Post \\
\hline 24 & Larry Robbins & Kurucusu & Glenview Capital Management \\
\hline 25 & Leonard Lauder & CEO ve YKB & Estée Lauder \\
\hline 26 & Lewis E. Platt & YKB ve CEO & Boeing \\
\hline 27 & Mauricio Macri & Önceki Buenos Aires Belediye Başkanı & Arjantin Devlet Başkanı \\
\hline 28 & Mike Eskew & YKB ve CEO & UPS \\
\hline 29 & Mitchell J. Blutt & CEO & Consonance Capital \\
\hline 30 & Mortimer Zuckerman & YKB ve editor-in-chief & U.S. News \& World Report \\
\hline 31 & Norman Blackwell / Baron Blackwell & YKB & Interserve \\
\hline 32 & Peter M. Nicholas & Kurucusu, CEO ve YKB & Boston Scientific \\
\hline 33 & Rakesh Gangwal & YKB ve CEO & US Airways \\
\hline 34 & Robert Crveall & YKB ve CEO & American Airlines \\
\hline 35 & Robert S. Kapito & Kurucusu ve Başkan & BlackRock \\
\hline 36 & Robert Wolf & Başkan ve CEO & UBS Investment Bank Americas \\
\hline 37 & Rosalind Brewer & $\mathrm{COO}$ & Starbucks \\
\hline 38 & Sundar Pichai & CEO & Google \\
\hline 39 & Terry Leahy & $\mathrm{CEO}$ & Tesco \\
\hline 40 & Vernon Hill & Kurucusu, YKB ve CEO & Commerce Bank \\
\hline 41 & Zeti Akhtar Aziz & Guvernör Bank Negara Malaysia & Central Bank of Malaysia \\
\hline
\end{tabular}

\section{Sonuç}

Bugünün İşletme ve İktisat Fakültelerinin temellerini teşkil eden ticaret eğitimlerinin sistemli bir şekilde Avrupa ve Amerika Eğitim Sistemlerinin içine nüfus edişi Sanayi Devrime ile birlikte olmuştur. Günümüzün saygın üniversitelerinin temellerini teşkil eden bu okullara özellikle tüccar kesimi büyük önem vermiş ve bu okulların gerek kuruluş aşamasında gerekse de gelişiminde maddi ve manevi desteklerini hiç esirgememişlerdir. Zamanla eğitim içerikleri değişmiş, güncellenmiş ve çağın gerektirdiği modern eğitim tekniklerini de kullanmaya başlamışlardır. Söz konusu bu okulların doğmasına esas neden ticaretin gerektirdiği nitelikli insan gücüne duyulan ihtiyaç olmuştur. Ekonomik büyümenin ekonomik kalkınma olmadan kalıcı olamayacağını anlayan batı dünyası, ekonomik büyümenin temelindeki insana yatırım yapmayı bir gereklilik olarak görmüş ve bunu sürdürmüştür.

Aslında ülkemizde de bu dönemler içerisinde ticaret eğitimi batılı örneklerinden hiç de geride kalmayacak şekilde verilmeye başlanmıştır. Osmanlı Devleti’nde ticareti en iyi yapan millet olan Rum Milleti, Heybeliada da ülkenin ilk özel ticaret okulu olan Elen Ticaret Mektebi 1831 yılında kurmuş ve ticaretin ihtiyacı olan tüccarları yetiştirmeye başlamıştır. Elen Ticaret Mektebinin çeşitli nedenlerle kapanmasını müteakip, ülkenin kamuya ait ilk ticaret okulu 1883 yılında kurulan Hamidiye Ticaret Mektebi Alisi olmuştur. Okul sonrasında İstanbul İktisadi ve Ticari İlimler Akademisi'ne dönüşmüş ve bugün ülkenin en büyük üniversitelerinden biri olan Marmara Üniversitesi’ne hayat vermiştir.

Finansal Destek: Yazar bu çalışma için finansal destek almamıştır.

\section{Kaynakça}

Beaud, M. (1983); “A History of Capitalism 1500-1980”, Monthly Review Press, New York, Sf.17 içinde Ekrem Erdem (2016); “Sanayi Devriminin Ardından Osmanlı Sanayileşme Hamleleri: Sanayi Politikalarının Dinamikleri ve Zaafiyetleri”, Erciyes Üniversitesi İktisadi ve İdari Bilimler Dergisi, Sayı:48, Temmuz-Aralık, Sf.19 
Bilgili, E. (1998.) "Dış Ticaret, Ekonomik Kalkınma ve Sanayi Devrimi”, Erciyes Üniversitesi İktisadi ve İdari Bilimler Fakültesi Dergisi, No:13, 35-39.

Blanchard, M. (2009). "From "Ecoles Supérieures de commerce" to "management schools": transformations and continuity in French business schools, European Journal of Education, 44(4), 586-604.

Chatziioannou, M. \& Tsilaga, F. (2015), "The "art of commerce": an outline of commercial education in twentieth-century Greece, The Historical Review / La Revue Historique,12, 215-228.

Edwards, J. R. (2011). “Accounting education in Britain during the early modern period”, Accounting History Review, 21(1), $37-67$.

Heining, A. (1902). “Commercial education in Germany and in England”, The School Review 10(2), 124-137.

Holdges, J. (1887). “Commercial education”, The North American Review, 144(366), 462-470.

Kaplan, A. (2014). "European management and European business schools: 1nsights from history of business schools", European Management Journal,32(4), 529-534.

McCrea, R. C. (1913). "The Work of the Wharton School of Finance and Commerce, Journal of Political Economy, 21(2),111-116.

Minot, S. (1887). "L'enseignement commercial et les ecoles de commerce en france et dans le monde entier", Journal de la Société Statistique de Paris, 28, 271-279.

Özince, E. (2007). "Uluslararası Bir Finansal Merkez Olarak Türkiye ve İstanbul”, 5-6 Aralık 2007 tarihlerinde Active Academy tarafından İstanbul'da düzenlenen Uluslararası Finans Zirvesi’nde yapılan açış konuşması (Bankacılar Dergisi), Sayı: 63, 3. 